Revue d'histoire de l'Amérique française

REVUE D.HISTOIRE DE L'AMÉRIQUE FRANÇAISE

\title{
Dom Paul Benoît et le Nouveau Monde (1850-1915)
}

\section{Maurice Dupasquier}

Volume 25, numéro 1, juin 1971

URI : https://id.erudit.org/iderudit/303042ar

DOI : https://doi.org/10.7202/303042ar

Aller au sommaire du numéro

Éditeur(s)

Institut d'histoire de l'Amérique française

ISSN

0035-2357 (imprimé)

1492-1383 (numérique)

Découvrir la revue

Citer cette note

Dupasquier, M. (1971). Dom Paul Benoît et le Nouveau Monde (1850-1915).

Revue d'histoire de l'Amérique française, 25(1), 89-90.

https://doi.org/10.7202/303042ar d'utilisation que vous pouvez consulter en ligne.

https://apropos.erudit.org/fr/usagers/politique-dutilisation/ 


\title{
NOTES DE RECHERCHE
}

\section{I \\ DOM PAUL BENOIT ET LE NOUVEAU MONDE (1850-1915)*}

\author{
MAURICE DUPASQUIER
}

Oublié aujourd'hui, Paul Benoît avait vécu une carrière active d'ecclésiastique ultramontain dans sa France natale jusqu'en 1891, puis au Manitoba jusqu'en 1915. C'est sa carrière nord-américaine qui est rappelée ici, attendu qu'il a travaillé à la construction de la mentalité toute particulière de "la France d'Amérique".

Issu d'une famille très attachée à l'Eglise catholique et à la monarchie, Benoît fut ordonné prêtre en 1874. Professeur et directeur au grand séminaire de Lons-le-Saunier, il y vécut les années où la Troisième République évoluait vers l'anticléricalisme. Puis, devenu religieux, il songea à s'expatrier.

En 1891, avec trois religieux et un convoi de colons, Benoît s'installait à Notre-Dame de Lourdes, au Manitoba, espérant œuvrer à la reconquête de l'Ouest canadien à la religion catholique sinon à la culture française.

Quatre autres convois de colons acheminés vers cette région permirent le peuplement rapide de cette première paroisse, comme aussi de celle de Saint-Claude. Benoît fonda également Saint-Oyend et Saint-Lupicin.

Les Chanoines réguliers, à leur apogée, gouvernaient les territoires situés entre Fannystelle à l'est, aux portes de Winnipeg, et Saint-Alphonse à l'ouest. Benoît était à la tête de seize maisons, divisées en deux groupes canoniques, celui du Nominingue, au Québec, et celui de Notre-Dame-de-Lourdes.

Ces religieux unissaient la liturgie et les observances pénitentielles aux œuvres pastorales des curés ordinaires. Onze ans après ses débuts en 1891, la petite communauté s'était multipliée onze fois. Cependant, l'expansion était insuffisante, et elle était due à des arrivées de religieux venus de France. Il semble que

* Résumé d'une thèse de doctorat ès lettres (histoire), présentée à l'Université Laval, en 1970, sous ce même titre. XLII-430 p.

RHAF, vol. 25, no 1 (juin 1971)

, [89] 
ce soit le régime très sévère de dom Benoit qui ait découragé ses jeunes recrues.

Les figures politiques locales avaient compris quelle influence électorale Benoît exerçait sur ses colons. Aussi s'arrachaient-elles son appui, qui alla de tout temps aux conservateurs.

Benoît a été le père du modus vivendi de 1898, par lequel les écoles ci-devant catholiques étaient proclamées nationales, ce qui leur permettait de recevoir les deniers publics, et par lequel le gouvernement du Manitoba leur versait des subventions sans exiger que leur programme d'instruction fût laïcisé.

Il participait activement au succès des conservateurs. C'est grâce à son influence auprès de Robert Rogers qu'il réussit à faire greffer à une nouvelle ligne de chemin de fer un tronçon d'environ deux milles, qui desservait Notre-Dame-de-Lourdes et sauvait sa paroisse d'une ruine certaine.

De 1893 à 1896 d'abord, il avait rédigé à nouveau et en abrégé son ouvrage sur La Vie des Clercs dans les siècles passés, dont le manuscrit primitif avait péri par les flammes. A partir de 1893 aussi, il publia de nombreux rapports statistiques sur son œuvre de colonisation: dans le Manitoba, la Semaine Religieuse de Québec, Paris-Canada, Bulletin de la Canadienne, les Cloches de Saint-Boniface, et la Croix de Paris.

Il revenait alors à la vie de l'esprit, fournissant des articles sur des thèmes divers et surtout de nombreuses charges contre le libéralisme, sa bête noire. Publié sous forme d'articles d'abord, avant d'être réuni en brochure, son ouvrage, intitulé L'anglomanie au Canada, avait au tout début de 1900 soulevé une tempête de protestations. Sa Vie de Mgr Taché, archevêque de St-Boniface, parue en 1905, reçut un accueil plus discret. Benoît fut le conseiller écouté du successeur de Taché, Mgr Langevin. Les deux hommes, proches au plan des idées, avaient toutefois des caractères très différents.

Ayant refusé des transformations imposées à sa congrégation, Benoît fut destitué de toutes ses fonctions à la date du 28 mars 1910 et envoyé à la retraite. Sécularisé avec dix de ses collègues le 25 septembre 1913, il entreprit de nouvelles luttes contre les réformes. Alors qu'il attendait en France une décision de Benoît XV, il mourut à Saint-Chamond le 19 novembre 1915.

On doit à Paul Benoît treize ouvrages principaux, dont cinq n'ont pas été publiés. 